\title{
Rising Thyroid Disorders Among Type 2 Diabetic Mellitus Patients: Case-Control Study
}

\author{
Abdulbari Bener ${ }^{1,2,6}$, Abdulla O.A.A. Al-Hamaq ${ }^{3}$, Cem Cahit Barışık ${ }^{4}$, Yaşar Özdenkaya ${ }^{5}$ \& Mustafa Öztürk ${ }^{6}$ \\ ${ }^{1}$ Department of Biostatistics \& Medical Informatics, Cerrahpaşa Faculty of Medicine, Istanbul University, \\ Istanbul, Turkey \\ ${ }^{2}$ Department of Evidence for Population Health Unit, School of Epidemiology and Health Sciences, The \\ university of Manchester, Manchester, UK \\ ${ }^{3}$ Qatar Diabetic Associations and Qatar Foundation, Doha, Qatar \\ ${ }^{4}$ Departments Radyology and Pathology, Medipol School of Medicine, Istanbul Medipol University, Istanbul, \\ Turkey \\ ${ }^{5}$ Department of Surgery, Medipol School of Medicine, Istanbul Medipol University, Istanbul, Turkey \\ ${ }^{6}$ Department of Endocrinology, Medipol International School of Medicine, Istanbul Medipol University, Istanbul, \\ Turkey \\ Correspondence: Prof. Abdulbari Bener, Advisor to WHO, Professor of Public Health, Dept. of Biostatistics \& \\ Medical Informatics, Cerrahpaşa Faculty of Medicine, Istanbul University and Istanbul Medipol University, \\ International School of Medicine, 34098 Cerrahpasa-Istanbul, Turkey. Tel: 90-212-414 3041. Fax: \\ 90-212-632-0033. E-mail: abdulbari.bener@istanbul.edu.tr
}

Received: May 25, 2018 Accepted: June 28, 2018 Online Published: July 11, 2018

doi:10.5539/gjhs.v10n8p61 URL: https://doi.org/10.5539/gjhs.v10n8p61

\begin{abstract}
Aim: The objective of study to explore the association between thyroid dysfunction and Type 2 diabetes mellitus (T2DM) related to family history and co-morbid conditions.

Methods: This was a case and control study, 762 T2DM patients and 762 control study participants were enrolled, aged between 25 and 65 years. The study based on biochemistry parameters included: fasting blood glucose levels (FBG), glycosylated hemoglobin (HbA1c), serum cholesterol, triglycerides, high density lipoprotein (HDL), low density lipoprotein (LDL), thyroid stimulating hormone (TSH), T3, and T4.
\end{abstract}

Results: There were statistically significant differences between T2DM patients and control subjects regarding BMI, physical activity, smoking, metabolic syndrome, hypertension, family history thyroid nodules, and number of sleeping hours. The study found statistically significant differences between T2DM and control subjects on calcium ( $\mathrm{p}=0.028)$, magnesium $(\mathrm{p}<0.001)$, potassium $(\mathrm{p}<0.001)$, phosphorous $(\mathrm{p}=0.038)$, fasting blood glucose $(p<0.001)$, HbA1c $(p<0.001)$, LDL $(p=0.002)$, albumin $(p<0.001)$, billirubin $(p=0.015)$, triglyceride $(p<0.001)$, SBP $(p=0.009)$ and, DBP $(p=0.002)$, TSH $(p<0.001), T 3(p<0.001)$, and T4 $(p<0.001)$. There were statistically significant differences between subjects with and those without thyroid nodules for calcium $(\mathrm{p}<0.001)$, magnesium $(\mathrm{p}<0.001)$, phosphorous $(\mathrm{p}=0.022)$, HDL $(\mathrm{p}=0.050)$, TSH $(\mathrm{p}<0.001), \mathrm{T} 3(\mathrm{p}<0.001)$, and T4 $(\mathrm{p}<0.001)$. Multivariable stepwise logistic regression analysis showed that TSH mIU/L $(<0.001)$, HbA1c $(p<0.001)$, family history of thyroid $(\mathrm{p}<0.001)$, Waist circumference, $(\mathrm{p}<0.001)$, SBP $\mathrm{mmHg}(\mathrm{p}=0.002)$, [DBP $\mathrm{mmHg}(\mathrm{p}=$ $0.003)$, BMI ( $p=0.006)$, Serum Calcium level $(\mathrm{mmol} / \mathrm{L})(p<0.001]$, and family history of $\mathrm{DM}(\mathrm{p}=0.015)$ were considered at higher risk as a predictors of thyroid amongT2DM patients.

Conclusion: The study found a high prevalence of thyroid dysfunction in Turkish T2DM patients compared to the general population. This study suggests that obesity, $\mathrm{HbAlc}$, the environment, and genetic susceptibility among T2DM, may increase the risk of thyroid disease and cancer.

Keywords: epidemiology, thyroid disorder, T2DM, metabolic syndrome, prevention

\section{Introduction}

Type 2 diabetes mellitus (T2DM) and thyroid dysfunction are both the main threats world wide and affetc the health and economic of most developed and developing countries (Alberti et al., 2009; Bener et al., 2009). T2DM 
very rapidly increasing the risk of coronary heart diseases (Al-Wazzan et al., 2010; Bener at al., 2014; Bener et al., 2016) and thyroid dysfunction in the long term (Akbar et al., 2006; Marrero, 2009; Papazafiropoulou et al., 2010; Ghazali \& Abbiyesuku, 2010; Wang et al., 2015; Centeno Maxzud et al., 2016; Sarfo-Kantanka et al., 2017; Malaguarnera et al., 2017; Bener et al., 2018). Although, lifestyle factors, regular physical exercise, appropriate diet are main essential elements in the prevention of T2DM (Bener et al., 2016).

Thyroid disorders and diabetes are two most common endocrinological medical conditions seen in general clinical medical practice (Al-Wazzan et al., 2010). The concurrence of the two medical conditions in the same individual can lead to achieving good glycemic control and prevent the cardiovascular risk associated with diabetes. (Alberti et al., 2009; Bener et al., 2009; Bener et al., 2016) Although, several studies have shown a higher prevalence of thyroid dysfunction occurs in T2DM patients and vice-versa (Akbar et al., 2006; Papazafiropoulou et al., 2010; Ghazali \& Abbiyesuku, 2010; Wang et al., 2015; Malaguarnera et al., 2017).

T2DM is very common disease related to risk factor such as overweight, obesity, sedentary lifestyles, stress, hypertension, hyperglycemia, dyslipidemia ( Bener et al., 2009; Bener et al., 2016; Marrero, 2009; Wang et al., 2015; Centeno Maxzud et al., 2016; Sarfo-Kantanka et al., 2017; Ghazali \& Abbiyesuku, 2010). Several authors reported that T2DM as risk factor for coronary heart disease and thyroid thyroid nodules (Akbar et al., 2006; Marrero, 2009 ; Papazafiropoulou et al., 2010; Ghazali \& Abbiyesuku, 2010; Wang et al., 2015; Centeno Maxzud et al., 2016; Sarfo-Kantanka et al., 2017; Malaguarnera et al., 2017). The range of thyroid disorders such as diabetes is very wide; and it is frequently does change in epidemiology, this has been observed by iodine levels seen in the population (Marrero, 2009; Weetman, 2011; Wang et al., 2015; Centeno Maxzud et al., 2016). In some parts of the world where intake of iodine, a major component of thyroid hormones which represent the most common cause of thyroid pathology (Sarfo-Kantanka et al., 2017).

The metabolic syndrome, obesity, and diabetes are considered major risk factors for thyroid dysfunction risk or thyroid cancer development (Leitzmann e al., 2010; Sarfo-Kantanka et al., 2011; Bener et al., 2018). The aim of this study was to explore the association between thyroid dysfunction and T2DM patients in relation to age, sex, lifestyle, obesity, family history and other co-morbid contributing risk factors.

\section{Subjects and Methods}

This study was designed as a case and control based on subjects age ranged between from 25 to 65 who visited the diabetes clinics, endocrinology clinics, thyroid surgery and outpatient clinics at the Istanbul University of Medipol, Medipol Hospital Groups from January 2016 to April 2018. This case and control study was based on 762 type 2 diabetic and 762 control subjects.

\subsection{Laboratory Measurements}

Case T2DM patients were considered according to American Diabetes Association (ADA 2014) and International Diabetes Federation (IDF) World Health Organization (WHO) (Alberti et al. 2009; Bener et al., 2009; Bener et al., 2014; ADA, 2014) (i.e (1) fasting venous plasma glucose concentration $\geq 7.0 \mathrm{mmol} / 1$ (2) 2-hour venous plasma glucose concentration $\geq 11.1 \mathrm{mmol} / \mathrm{l}$; or $(3) \mathrm{HbAlc} \geq 6.5$. Subjects reporting a history of DM and receiving antihyperglycemic therapy also were considered having diabetes mellitus. The inclusion criteria comprised of diagnosis of T2DM in conformity with international standards by ADA and IDF (Alberti et al., 2009; Bener et al., 2009; ADA, 2010).

A subject was included in the control group (subjects without diabetes) if FPG was less than $7.0 \mathrm{mmol} / \mathrm{L}$ (126 $\mathrm{mg} / \mathrm{dL}$ ) and $\mathrm{HbA} 1 \mathrm{c}$ less than $48 \mathrm{mmol} / \mathrm{mol}(6.5 \%)$ and no use of diabetes medications was reported.

\subsection{Thyroid Evaluation}

Thyroid function was evaluated by measuring thyroid stimulating hormone (Gharib et al., 2005) (TSH), T3, and T4, using immunochemoluminescent assays by an automated analyzer (Immulite, 2000; Diagnostic Products, Los Angeles, CA, USA). Also, thyroid fine needle aspiration biopsy was considered for patients if thyroid nodules were greater than $1.00 \mathrm{~cm}$ (Bener et al., 2018). Further, the study based socio-demographic characteristics, lifestyle habits and biochemical parameters, physical exercise and family history and co-morbid medical conditions.

The SPSS computer software for Windows, Version 22.0 was used to determine the significance of differences between mean values of two continuous variables. Chi-square and Fischer's exact tests were conducted for the differences between two or more categorical variables. Multivariate logistic regression analysis was used to assess the relationship between dependent and independent variables and to determine possible the risk factors for the existing of thyroid nodules among T2DM patients and $\mathrm{p}$ value less than 0.05 considered significant. 


\section{Results}

Table 1 summarizes the study socio-demographic variables of T2DM patients and control subjects. As can be seen from this table most of variables BMI, physical activity, smoking, metabolic syndrome, hypertension, family history thyroid nodules, and number of sleeping hours appeared statistically significant differences between T2DM patients and control subjects.

Table 1. Socio-demographic and clinical characteristics of studied T2DM patients and control subjects $(\mathrm{N}=1,524)$

\begin{tabular}{|c|c|c|c|}
\hline & $\begin{array}{l}\text { T2DM } \\
n=762\end{array}$ & $\begin{array}{l}\text { Control } \\
n=762\end{array}$ & \\
\hline Age groups (in years) & & & \\
\hline$<40$ & $201(26.4)$ & $207(27.2)$ & \multirow{4}{*}{0.100} \\
\hline $40-49$ & $177(23.2)$ & $212(27.7)$ & \\
\hline $50-59$ & $168(22.0)$ & $161(21.2)$ & \\
\hline$>60$ and above & $216(23.8)$ & $182(23.9)$ & \\
\hline \multicolumn{4}{|l|}{ Gender } \\
\hline Male & $312(40.9)$ & $335(44.0)$ & \multirow{2}{*}{0.233} \\
\hline Female & $450(59.1)$ & $427(56.0)$ & \\
\hline \multicolumn{4}{|l|}{ BMI $\left(\mathrm{kg} / \mathrm{m}^{2}\right)$} \\
\hline Normal $\left(<25 \mathrm{~kg} / \mathrm{m}^{2}\right)$ & $213(28.0)$ & $284(37.4)$ & \\
\hline Overweight $\left(29-30 \mathrm{~kg} / \mathrm{m}^{2}\right)$ & $342(44.9)$ & $342(45.0)$ & \multirow{2}{*}{0.001} \\
\hline Obese $\left(>30 \mathrm{~kg} / \mathrm{m}^{2}\right)$ & $207(27.1)$ & $134(17.6)$ & \\
\hline \multicolumn{4}{|l|}{ Physical activity } \\
\hline Yes & $214(28.1)$ & $202(28.1)$ & \multirow{2}{*}{0.026} \\
\hline No & $548(73.9)$ & $560(73.5)$ & \\
\hline \multicolumn{4}{|l|}{ Smoking status } \\
\hline Never & $634(83.2)$ & $561(73.6$ & \multirow{3}{*}{0.001} \\
\hline Current smoker & $85(11.2)$ & $98(12.9)$ & \\
\hline Past smoker & $43(5.6)$ & $103(13.5)$ & \\
\hline \multicolumn{4}{|l|}{ Metabolic Syndrome ATP -III } \\
\hline Yes & $267(35.0)$ & $76(10.0)$ & \multirow{2}{*}{0.001} \\
\hline No & $495(65.0)$ & $686(90.0)$ & \\
\hline \multicolumn{4}{|c|}{ Family history of hypertension } \\
\hline Yes & $151(19.8)$ & $102(13.4)$ & \multirow{2}{*}{0.001} \\
\hline No & $611(80.2)$ & $660(86.6)$ & \\
\hline \multicolumn{4}{|c|}{ Family history of Thyroid nodule: } \\
\hline Yes & $108(14.2)$ & $46(6.0)$ & \multirow{2}{*}{0.001} \\
\hline No & $654(85.8)$ & $716(94.0)$ & \\
\hline Number of Sleeping hours & $5.90 \pm 0.92$ & $6.52 \pm 1.16$ & 0.001 \\
\hline BMI kg/m² & $27.60 \pm 4.54$ & $26.50 \pm 6.39$ & 0.001 \\
\hline
\end{tabular}

Table 2 presents the biochemistry parameters value among value among T2DM and control subjects. The analysis revealed significant differences between T2DM and control subject for calcium $(\mathrm{p}=0.028)$, magnesium $(\mathrm{p}<0.001)$, potassium $(p<0.001)$, phosphorous $(p=0.038)$, fasting blood glucose $(p<0.001), \operatorname{HbA1c}(p<0.001)$, LDL $(p=0.002)$, 
albumin $(\mathrm{p}<0.001)$, billirubin $(\mathrm{p}=0.015)$, triglyceride $(\mathrm{p}<0.001)$, SBP $(\mathrm{p}=0.009)$ and, DBP $(\mathrm{p}=0.002)$, TSH $(p<0.001), T 3(p<0.001)$, and T4 $(p<0.001)$. Statistically significant differences were found between T2DM and control subject regarding.

Table 2. Clinical biochemistry baseline value among T2DM and control subjects $(\mathrm{N}=1,524)$

\begin{tabular}{|c|c|c|c|}
\hline \multirow{3}{*}{ Variables } & \multirow{3}{*}{$\begin{array}{l}\text { T2DM } \\
\text { N =762 } \\
\text { Mean } \pm \text { SD }\end{array}$} & \multicolumn{2}{|l|}{ Control } \\
\hline & & $N=762$ & $P$ value \\
\hline & & Mean \pm SD & \\
\hline Hemoglobin $(\mathrm{g} / \mathrm{dL})$ & $12.85 \pm 2.32$ & $13.04 \pm 2.46$ & 0.285 \\
\hline Magnesium $(\mathrm{mmol} / \mathrm{L})$ & $0.79 \pm 0.08$ & $0.92 \pm 0.09$ & $<0.001$ \\
\hline Potassium $(\mathrm{mmol} / \mathrm{L})$ & $3.72 \pm 0.91$ & $4.46 \pm 0.76$ & $<0.001$ \\
\hline Calcium $(\mathrm{mmol} / \mathrm{L})$ & $1.74 \pm 0.67$ & $1.92 \pm 1.24$ & 0.001 \\
\hline Phosphorous (mmol/L) & $1.28 \pm 0.97$ & $1.20 \pm 0.63$ & 0.038 \\
\hline Creatinine $(\mathrm{mmol} / \mathrm{L})$ & $65.59 \pm 16.90$ & $63.83 \pm 12.22$ & 0.101 \\
\hline Fasting Blood Glucose(mmol/L) & $7.36 \pm 1.02$ & $6.27 \pm 1.42$ & $<0.001$ \\
\hline HbAlc & $7.58 \pm 1.47$ & $6.02 \pm 1.32$ & $<0.001$ \\
\hline Cholesterol (mmol/L) & $4.80 \pm 1.04$ & $3.23 \pm 1.19$ & $<0.001$ \\
\hline $\mathrm{HDL}(\mathrm{mmol} / \mathrm{L})$ & $1.34 \pm 0.19$ & $1.31 \pm 0.14$ & 0.911 \\
\hline $\mathrm{LDL}(\mathrm{mmol} / \mathrm{L})$ & $1.91 \pm 0.50$ & $2.11 \pm 0.94$ & 0.002 \\
\hline Albumin $(\mathrm{mmol} / \mathrm{L})$ & $40.67 \pm 9.22$ & $36.84 \pm 10.18$ & $<0.001$ \\
\hline Billirubin $(\mathrm{mmol} / \mathrm{L})$ & $9.19 \pm 5.25$ & $9.84 \pm 4.18$ & 0.015 \\
\hline Triglyceride $(\mathrm{mmol} / \mathrm{L})$ & $1.96 \pm 1.03$ & $1.23 \pm 0.70$ & $<0.001$ \\
\hline Uric Acid $(\mathrm{mmol} / \mathrm{L})$ & $271.6 \pm 76.87$ & $293.5 \pm 78.6$ & $<0.001$ \\
\hline Systolic Blood Pressure mm Hg & $129.98 \pm 15.06$ & $126.89 \pm 15.98$ & 0.009 \\
\hline Diastolic Blood Pressure mm Hg & $78.96 \pm 10.82$ & $77.64 \pm 9.81$ & 0.002 \\
\hline Thyroid stimulating hormone -TSH & $2.70 \pm 1.00$ & $1.95 \pm 1.13$ & $<0.001$ \\
\hline $\mathrm{T} 3$ & $1.86 \pm 1.01$ & $1.21 \pm 0.71$ & $<0.001$ \\
\hline $\mathrm{T} 4$ & $1.21 \pm 0.71$ & $0.88 \pm 0.31$ & $<0.001$ \\
\hline
\end{tabular}

TSH (reference range, $0.35-4.0 \mathrm{mIU} / \mathrm{l})$, free tri-iodothyronine (FT3; reference range, $1.71-4.71 \mathrm{pg} / \mathrm{ml}$ ), and free thyroxine (FT4; reference range, $0.8-1.9 \mathrm{ng} / \mathrm{dl}$ ).

The results of the Clinical biochemistry comparison for T2DM with thyroid and without thyroid nodules are presented in Table 3 . As can be seen from this table, the results were statistically significant differences for calcium $(\mathrm{p}<0.001)$, magnesium $(\mathrm{p}<0.001)$, phosphorous $(\mathrm{p}=0.022), \mathrm{HDL}(\mathrm{p}=0.050), \mathrm{TSH}(\mathrm{p}<0.001), \mathrm{T} 3(\mathrm{p}<0.001)$, and T4 $(\mathrm{p}<0.001)$ between subjects with and those without thyroid nodules. 
Table 3. Clinical biochemistry baseline value among T2DM with thyroid nodules and without thyroid nodules

\begin{tabular}{|c|c|c|c|}
\hline Variables & $\begin{array}{l}\text { T2DM } \\
\text { With thyroid nodule } \\
\mathrm{N}=192 \\
\text { Mean } \pm \text { SD }\end{array}$ & $\begin{array}{l}\text { T2DM } \\
\text { Without thyroid nodule } \\
\mathbf{N}=\mathbf{5 7 0} \\
\text { Mean } \pm \text { SD }\end{array}$ & P value \\
\hline Hemoglobin $(\mathrm{g} / \mathrm{dL})$ & $12.80 \pm 2.35$ & $13.01 \pm 2.48$ & 0.246 \\
\hline Magnesium (mmol/L) & $0.76 \pm 0.10$ & $0.92 \pm 0.11$ & $<0.001$ \\
\hline Potassium $(\mathrm{mmol} / \mathrm{L})$ & $3.48 \pm 0.36$ & $3.80 \pm 0.25$ & 0.462 \\
\hline Serum Calcium level $(\mathrm{mmol} / \mathrm{L})$ & $1.55 \pm 0.44$ & $1.81 \pm 0.72$ & $<0.001$ \\
\hline Phosphorous (mmol/L) & $1.41 \pm 0.30$ & $1.43 \pm 0.65$ & 0.022 \\
\hline Creatinine $(\mathrm{mmol} / \mathrm{L})$ & $65.21 \pm 15.34$ & $65.71 \pm 17.42$ & 0.824 \\
\hline Fasting Blood Glucose $(\mathrm{mmol} / \mathrm{L})$ & $7.33 \pm 0.91$ & $7.59 \pm 1.00$ & 0.694 \\
\hline $\mathrm{HbAlc}$ & $7.49 \pm 0.97$ & $7.28 \pm 1.08$ & 0.008 \\
\hline Cholesterol $(\mathrm{mmol} / \mathrm{L})$ & $4.79 \pm 1.00$ & $4.80 \pm 1.05$ & 0.969 \\
\hline $\mathrm{HDL}(\mathrm{mmol} / \mathrm{L})$ & $1.94 \pm 0.73$ & $1.13 \pm 0.36$ & 0.001 \\
\hline $\mathrm{LDL}(\mathrm{mmol} / \mathrm{L})$ & $1.91 \pm 0.76$ & $1.58 \pm 1.00$ & 0.045 \\
\hline Albumin $(\mathrm{mmol} / \mathrm{L})$ & $40.1 \pm 9.55$ & $40.8 \pm 7.50$ & 0.376 \\
\hline Billirubin $(\mathrm{mmol} / \mathrm{L})$ & $9.63 \pm 3.62$ & $9.02 \pm 3.58$ & 0.253 \\
\hline Triglyceride (mmol/L) & $1.93 \pm 0.94$ & $1.97 \pm 0.79$ & 0.736 \\
\hline Uric Acid (mmol/L) & $271.8 \pm 70.3$ & $270.4 \pm 79.0$ & 0.844 \\
\hline Systolic Blood Pressure mm Hg & $130.6 \pm 15.6$ & $127.9 \pm 15.4$ & 0.036 \\
\hline Diastolic Blood Pressure mm Hg & $79.4 \pm 9.4$ & $77.8 \pm 9.6$ & 0.045 \\
\hline Thyroid stimulating hormone -TSH & $2.91 \pm 0.86$ & $2.63 \pm 0.99$ & $<0.001$ \\
\hline $\mathrm{T} 3$ & $2.19 \pm 0.97$ & $1.75 \pm 1.12$ & $<0.001$ \\
\hline $\mathrm{T} 4$ & $1.50 \pm 1.02$ & $1.10 \pm 0.55$ & $<0.001$ \\
\hline
\end{tabular}

The results of multiple logistic regression analysis are shown in Table 4. TSH mIU/L [OR 3.35 95\% CI 1.73-5.98, $<0.001$ ], HbA1c [ OR $2.9595 \%$ CI 1.73-4.74, p< 0.001 ], family history of thyroid [OR $2.83 \backslash 95 \%$ CI $1.65-4.57$, $\mathrm{p}=0.001$ ], Waist circumference, cm [ OR 2.62 95\% CI 1.89-3.53, <0.001], SBP mmHg [OR $1.4595 \%$ CI $1.18-1.85, \mathrm{p}=0.002$ ], [DBP mmHg [1.57 95\% CI 1.24-1.99, $\mathrm{p}=0.003$ ], BMI [ OR $2.5595 \%$ CI 1.76-4.43, $\mathrm{p}=$ 0.006 ], Serum Calcium level (mmol/L) OR $2.1295 \%$ CI 1.10-3.66, $\mathrm{p}=0.009$ ], and family history of DM [OR 1.81 $95 \%$ CI 1.22-2.64, $\mathrm{p}=0.015$ ] were considered at higher risk as a predictors of thyroid amongT2DM patients.

Table 4. Multivariate logistic regression analysis for predictors presence of thyroid disorder among T2DM patients

\begin{tabular}{llll}
\hline Independent Variables & Odds Ratio & $\mathbf{9 5 \%}$ Confidence Interval & P Value \\
\hline $\mathrm{TSH}, \mathrm{mIU} / \mathrm{L}$ & 3.35 & $1.73-5.98$ & $<0.001$ \\
$\mathrm{HbA1C}$ & 2.95 & $1.73-4.74$ & $<0.001$ \\
Family history of thyroid & 2.83 & $1.65-4.57$ & $<0.001$ \\
Waist circumference, cm & 2.62 & $1.89-3.53$ & $<0.001$ \\
Systolic blood pressure, $\mathrm{mmHg}$ & 1.45 & $1.18-1.85$ & 0.002 \\
Diastolic blood pressure, $\mathrm{mmHg}$ & 1.57 & $1.24-1.99$ & 0.003 \\
BMI $\left(\mathrm{kg} / \mathrm{m}^{2}\right)$ & 2.55 & $1.76-4.43$ & 0.006 \\
Serum Calcium level $(\mathrm{mmol} / \mathrm{L})$ & 2.12 & $1.10-3.66$ & 0.009 \\
Family history of DM & 1.81 & $1.22-2.64$ & 0.015 \\
\hline
\end{tabular}




\section{Discussion}

There are few studies comparing the prevalence of T2DM with thyroid dysfunction patients and controls subject as worldwide. Our study has revealed a higher rate of thyroid nodules in T2DM subjects compared to control subjects. The finding of this study is consistent with those based in Kuwait Al-Wazzan et al. (2010), Greece (Papazafiropoulou et al., 2010), Saudi Arabia (Akbar et al., 2006), Nigeria (Ghazali et al., 2010), Ghana (Sarfo-Kantanka et al., 2010) and Jordan (Radaideh et al., 2004) who recorded significantly higher prevalence of thyroid nodules in T2DM subjects compared to controls, with prevalence ranging between $10 \%$ and $40 \%$ amongT2DM subjects (Chen et al., 2010). However, these large variations could be based on different diagnostic criteria of dysfunction, geographical locations, different sensitivities of the TSH assays and the large population diversity (Chen et al., 2010; Palma et al., 2013).

Also, T2DM is considered as risk factor and complication concerning thyroid. It is worth to note that very impress prevention of T2DM is necessary to reduce the increases rate of thyroid in the population. Further, the current subjects with T2DM also had a higher prevalence and larger thyroid nodules size which is confirmative with an earlier reported strong correlations between insulin resistance and thyroid nodule size (Al-Wazzan et al., 2010; Sarfo-Kantanka et al., 2017).

In fact, T2DM and thyroid dysfunction are highly correlated as the two commonest endocrinological medical conditions reported in clinical practice (Akbar et al., 2006; Marrero, 2009; Papazafiropoulou et al., 2010; Ghazali \& Abbiyesuku, 2010; Wang et al., 2015; Centeno Maxzud et al., 2016; Sarfo-Kantanka et al., 2017; Malaguarnera et al., 2017). Further, some authors indicated that thyroid volume are associated with iodine deficiency and supply, Body Mass Index, gender, age, cigarettes smoking, genetic factors, FBG and T2DM severity (Bener et al., 2009; Duran et al., 2014; Kir et al., 2018; Rezzonico et al., 2008; Bener et al., 2018). The current study is consistent with earlier reported the correlation between metabolic disorders characterized by insulin resistance and the risk of thyroid cancer (Marrero, 2010; Ghazali et al., 2010; Chen et al., 2010; Kir et al., 2018; Bener et al., 2018).

Furthermore, increases thyroid cancer risk in diabetics might be related to several factors including, abnormal $\mathrm{HbA1C}$ and metabolic syndrome, triglyceride levels, obesity, dietary, and lifestyle (Marrero, 2010; Aschebrook-Kilfoy et al., 2011; Bener et al., 2018). Obese subjects were at ten times more risk of developing diabetes (Aschebrook-Kilfoy et al., 2011), and obesity was correlated with an increased risk of thyroid cancer (Leitzmann et al., 2010). Our sample demonstrated significant prevalence of thyroid dysfunction among T2DM compared to controls.

\section{Conclusion}

The study found very high rate of thyroid dysfunction in Turkish T2DM patients compared to the general population. This study suggests that obesity, $\mathrm{HbA1c}$, the environment, and genetic susceptibility among T2DM, may increase the risk of thyroid dysfunction and cancer. The high prevalence of thyroid dysfunction among T2DM which may require routinely screening for thyroid disease.

\section{Key Messages}

1. There is a strong positive associations between the T2DM and thyroid dysfunction population.

2. This study reveals that an increase in thyroid dysfunction might be caused by increases in Metabolic Syndrome, $\mathrm{HbA1C}$, diabetes and obesity.

\section{Contributors}

$\mathrm{AB}, \mathrm{MÖ}$ and YÖ designed and supervised the study and were involved in data collection, statistical analysis and the writing of the paper. AOAA, CCB were involved in study designed, interpretation of data and writing of the manuscript. All authors approved the final version.

\section{Acknowledgment}

This work was generously supported and funded by the Qatar Diabetes Association, Qatar Foundation. The authors would like to thank the Istanbul Medipol University for their support and ethical approval (Research Protocol and IRB\# 10840098-604.01.01-E.8421).

\section{Conflict of Interest}

No conflict of interest was declared by the authors.

\section{Financial Disclosure}

The authors declared that this study has received no financial support. 


\section{References}

Akbar, D. H., Ahmed, M. M., \& Al-Mughales, J. (2006). Thyroid dysfunction and thyroidautoimmunity in Saudi type 2 diabetics. Acta Diabetologia; 43(1), 14-8. https://doi.org/10.1007/s00592-006-0204-8

Alberti, K. G. M. M., Eckel, R. H., Grundy, S. M., Zimmet, P. Z., Cleeman, J. I., Donato, K. A., ... \& Smith, S. C. (2009). Harmonizing the metabolic syndrome: a joint interim statement of the international diabetes federation task force on epidemiology and prevention; national heart, lung, and blood institute; American heart association; world heart federation; international atherosclerosis society; and international association for the study of obesity. Circulation, 120(16), 1640-1645. https://doi.org/10.1161/CIRCULATIONAHA.109.192644

Al-Wazzan, H. T., Daban, A. H., Askar, R. A., \& El-Shazly, M. K. (2010). Prevalence and associated factors of thyroid dysfunction among type 2 diabetic patients in Kuwait. Alex Bull., 46(2), 141-148.

American Diabetes Association. (2014). Diagnosis and classification of diabetes mellitus. Diabetes care, 37(Supplement 1), S81-S90. https://doi.org/10.2337/dc10-S062

Aschebrook-Kilfoy, B., Sabra, M. M., Brenner, A., Moore, S. C., Ron, E., Schatzkin, A., ... \& Ward, M. H. (2011). Diabetes and thyroid cancer risk in the National Institutes of Health-AARP Diet and Health Study. Thyroid, 21(9), 957-963. https://doi.org/10.1089/thy.2010.0396

Bener, A., Al-Hamaq, A. O., Kurtulus, E. M., Abdullatef, W. K., \& Zirie, M. (2016). The role of vitamin D, obesity and physical exercise in regulation of glycemia in Type 2 Diabetes Mellitus patients. Diabetes \& Metabolic Syndrome: Clinical Research \& Reviews, 10(4), 198-204. https://doi.org/10.1016/j.dsx.2016.06.007

Bener, A., Al-Laftah, F., Al-Hamaq, A. O., Daghash, M., \& Abdullatef, W. K. (2014). A study of diabetes complications in an endogamous population: an emerging public health burden. Diabetes \& Metabolic Syndrome: Clinical Research \& Reviews, 8(2), 108-114. https://doi.org/10.1016/j.dsx.2014.04.005

Bener, A., Özdenkaya, Y., Barışık, C. C., \& Öztürk, M. (2018). The Impact of Metabolic Syndrome on Increased Risk of Thyroid Nodules and Size. Health Services Research and Managerial Epidemiology, 5:1-6, DOI: $10.1177 / 2333392818775517$.

Ghorbani, R., Eskandarian, R., Rashidy-Pour, A., Khamseh, M. E., \& Malek, M. (2012). Prevalence of metabolic syndrome according to ATPIII and IDF criteria in the Iranian population. Koomesh, 65-75. https://doi.org/10.1089/met.2008.0077

Brunn, J., Block, U., Ruf, G., Bos, I., Kunze, W. P., \& Scriba, P. C. (1981). Volumetric analysis of thyroid lobes by real-time ultrasound (author's transl). Deutsche medizinische Wochenschrift (1946), 106(41), 1338-1340. https://doi.org/10.1055/s-2008-1070506

Diez, J. J., Sánchez, P., \& Iglesias, P. (2011). Prevalence of thyroid dysfunction in patients with type 2 diabetes. Experimental and Clinical Endocrinology \& Diabetes, 119(04), 201-207.

Chen, G., Wu, J., Lin, Y., Huang, B., Yao, J., Jiang, Q., ... \& Lin, L. (2010). Associations between cardiovascular risk, insulin resistance, $\beta$-cell function and thyroid dysfunction: a cross-sectional study on the She ethnic minority group of Fujian Province in China. European journal of endocrinology. https://doi.org/10.1530/EJE-10-0710

Duran, A. O., Anil, C., Gursoy, A., Nar, A., Inanc, M., Bozkurt, O., \& Tutuncu, N. B. (2014). Thyroid volume in patients with glucose metabolism disorders. Arquivos Brasileiros de Endocrinologia \& Metabologia, 58(8), 824-827. https://doi.org/10.1590/0004-2730000003418

Gharib, H., Tuttle, R. M., Baskin, H. J., Fish, L. H., Singer, P. A., \& McDermott, M. T. (2005). Subclinical thyroid dysfunction: a joint statement on management from the American Association of Clinical Endocrinologists, the American Thyroid Association, and the Endocrine Society. Thyroid, 15(1), 24-28. https://doi.org/10.1210/jc.2004-1231

Ghazali, S. M., \& Abbiyesuku, F. M. (2010). Thyroid dysfunction in type 2 diabetics seen at the University College Hospital, Ibadan, Nigeria. Nigerian Journal of Physiological Sciences, 25(2), 173-179.

Kir, S., Aydin, Y., \& Coskun, H. (2018). Relationship between metabolic syndrome and nodular thyroid diseases. Scandinavian journal of clinical and laboratory investigation, 78(1-2), 6-10. https://doi.org/10.1080/00365513.2017.1402363

Leitzmann, M. F., Brenner, A., Moore, S. C., Koebnick, C., Park, Y., Hollenbeck, A., ... \& Ron, E. (2010). 
Prospective study of body mass index, physical activity and thyroid cancer. International journal of cancer, 126(12), 2947-2956. https://doi.org/10.1002/ijc.24913

Malaguarnera, R., Vella, V., Nicolosi, M. L., \& Belfiore, A. (2017). Insulin Resistance: Any Role in the Changing $\begin{array}{lllll}\text { Epidemiology of Thyroid Cancer?. Frontiers in endocrinology, } 8, & 314 .\end{array}$ https://doi.org/10.3389/fendo.2017.00314

Marrero, D. G. (2009). The Prevention of type 2 diabetes: an overview. J Diabetes Sci Technol, 3, 756-760. https://doi.org/10.1177/193229680900300423

Palma, C. C. S. S. V., Pavesi, M., Nogueira, V. G., Clemente, E. L. S., Pereira, M. D. F. B. M., Pereira, L. C., ... \& dos Santos, S. C. F. (2013). Prevalence of thyroid dysfunction in patients with diabetes mellitus. Diabetology \& metabolic syndrome, 5(1), 58. https://doi.org/10.1186/1758-5996-5-58

Papazafiropoulou, A., Sotiropoulos, A., Kokolaki, A., Kardara, M., Stamataki, P., \& Pappas, S. (2010). Prevalence of thyroid dysfunction among Greek type 2 diabetic patients attending an outpatient clinic. Journal of clinical medicine research, 2(2), 75.

Radaideh, A. R., Nusier, M. K., Amari, F. L., Bateiha, A. E., El-Khateeb, M. S., Naser, A. S., \& Ajlouni, K. M. (2004). Thyroid dysfunction in patients with type 2 diabetes mellitus in Jordan. Saudi Med J, 25(8), 1046-50.

Rezzonico, J., Rezzonico, M., Pusiol, E., Pitoia, F., \& Niepomniszcze, H. (2008). Introducing the thyroid gland as another victim of the insulin resistance syndrome. Thyroid, 18(4), 461-464. https://doi.org/10.1089/thy.2007.0223

Sarfo-Kantanka, O., Sarfo, F. S., Ansah, E. O., Yorke, E., Akpalu, J., Nkum, B. C., \& Eghan, B. (2017). Frequency and determinants of thyroid autoimmunity in Ghanaian type 2 diabetes patients: a case-control study. $B M C$ endocrine disorders, 17(1), 2. https://doi.org/10.1186/s12902-016-0152-4

Wang, K., Yang, Y., Wu, Y., Chen, J., Zhang, D., Mao, X., ... \& Liu, C. (2015). The association between insulin resistance and vascularization of thyroid nodules. The Journal of Clinical Endocrinology \& Metabolism, 100(1), 184-192. https://doi.org/10.1210/jc.2014-2723

Weetman, A. P. (2011). Diseases associated with thyroid autoimmunity: explanations for the expanding spectrum. Clinical endocrinology, 74(4), 411-418. https://doi.org/10.1111/j.1365-2265.2010.03855.x

\section{Copyrights}

Copyright for this article is retained by the author(s), with first publication rights granted to the journal.

This is an open-access article distributed under the terms and conditions of the Creative Commons Attribution license (http://creativecommons.org/licenses/by/4.0/). 